\title{
THE POTENTIAL OF AUTONOMOUS AND CONNECTED SWEEPERS FOR SMART AND SUSTAINABLE CITIES
}

\author{
ISABELLE ROCHE CERASI \\ Dept of Mobility and Economics, SINTEF Community, Trondheim, Norway
}

\begin{abstract}
The objective of this research was to evaluate the potential of autonomous and connected sweepers for cleaning pavements and cycle ways. Supported by sustainable policies, the networks of cycle ways are growing considerably outside cities, and their maintenance is demanding in terms of economic resources. The current study examines the idea of replacing manned service vehicles by autonomous sweepers in urban areas. Autonomous sweepers could be operated from a control room to perform planned and on-demand cleaning tasks. Tests were carried out with the S100N Spring developed by the Chinese company Idriverplus Technology Co., Ltd. The sweeper performance and efficiency have been evaluated (1) with gravel, leaves, pine cones and rubbish in a closed test area and (2) in real conditions, on two pavements in Kongsberg (Norway). The results from the cleaning tests and the interactions with vulnerable road users are presented. Challenges and limitations of the technology are discussed. Keywords: autonomous sweepers, road maintenance, robot, safety, sustainable city.
\end{abstract}

\section{INTRODUCTION}

Climate change requires the shift from polluting, private cars to environmentally friendly transport modes. In Norway, the ambitious political and transport goals for reducing greenhouse gas emissions and increasing the number of pedestrians and cyclists require the challenges related to the maintenance of roads, footpaths, and cycle ways to be solved. Depending on the season, roads and paths are covered with snow, ice, gravel, leaves, other plant materials and rubbish. Public road owners have contracts with entrepreneurs who are responsible for cleaning and maintaining the networks of roads, cycle ways and pavements. The networks are extensive and quite demanding in terms of costs and human resources. In addition, the number of cycle ways is constantly increasing to satisfy the current demand by cyclists and to reach the national climate and transport goals. New cost-effective and environmentally friendly solutions are required today to ensure the safety and maintenance of pavements and cycle ways, vulnerable road users (pedestrians and cyclists) are expected to find. Batterypowered electric and autonomous sweepers are already available on the market. They have the potential to replace manned service vehicles at least in urban areas; vehicles with drivers could then focus on the long cycle ways around and outside cities. Prototype autonomous and connected sweepers and snow-removal robots offer different battery capacities and vehicle characteristics [10]. Their technical performances in real conditions are not currently known, and this makes it difficult for public or private companies who would like to buy or lease them to select those that could eventually best suit their requirements. This paper presents a research study carried out on behalf of the Road Directorate of the Norwegian Public Roads Administration (NPRA) and funded through the Research and Development MOVEMENT programme (2017-2021) [1]. The objectives of the program are (1) to provide knowledge on the current needs of pedestrians and cyclists concerning the usefulness of pavements and cycle ways; (2) to identify new methods, equipment and organisational structures that would contribute to efficient road operations and maintenance; and (3) to improve collaboration, contract design and follow-up of operations with entrepreneurs [1]. The programme also 
satisfies the national walking and cycling strategy, aiming to provide better mobility and quality of life for all citizens (including older people) [7]. Moreover, it complies with the objective of the national transport plan (2022-2033) in reducing the number of private cars in large cities [19].

To our knowledge, no research results have yet been published on the performance of autonomous sweepers based on data collection in real conditions. In collaboration with Test Arena Kongsberg - City\&Lab [25], which facilitates the cooperation between Norwegian partners in testing new technologies, an autonomous sweeper produced by Idriverplus Technology Co., Ltd, in China and supplied by the German distributor Spring Mobility GmbH (Germany) [23] was tested in the city of Kongsberg in Norway. The present paper describes field trials and measurements that have been conducted by SINTEF and the NPRA to evaluate the capabilities and performances of the sweeper in real conditions.

\subsection{Winter road maintenance}

Winter road maintenance includes diverse operations, such as de-icing with rock salt and sand, and snow ploughing. Norway spent 2.7 thousand million Norwegian kroner (NOK) in 2019 on winter road maintenance, representing $20 \%$ of the whole budget for road operations and maintenance [20]. During the winter of 2019-2020, 95,000 tonnes of salt, 185,000 tonnes of sand and approximately 9 million kilometres driven by service vehicles have been required to cover the network of national and county roads. The NPRA supervises the training of operators and foremen working for the entrepreneurs responsible for road operations and maintenance. National standards for road maintenance are provided, with manuals and textbooks defining requirements and practical aspects of the road operations [21]. These standards describe the conditions in which the use of de-icing chemicals, salt and sand is allowed on roads and cycle ways. Snow ploughing generally starts when a height of $5 \mathrm{~cm}$ of loose snow is reached. Cycling is more enjoyable and safer when the cycle ways are clean rather than slippery. Temperature and friction are important factors for ensuring good rolling conditions and providing safety and cycling comfort [5,6]. Effective winter maintenance of cycle ways positively affects the number of cyclists in winter [5], and cycling facilities are an important factor in increasing the number of commute-related cyclists [17]. Kummeneje et al. (2019) and Kummeneje (2020) showed that, in Norway, cyclists are worried about cycling in winter and that this greatly influenced whether they decided to cycle $[12,13]$. Moreover, Min et al. (2016) showed positive impacts of $10 \%$ improvement in road surface conditions in Canada on traffic safety and congestion, vehicle gas emissions and energy consumption [16]. Rapid changes in road conditions during winters [11], route optimisation for service vehicles [18] and the use of chemicals for road de-icing [26] are additional challenges to consider in reducing the negative effects on the environment. Winter is not the only challenging period in Norway. In autumn, leaves and other natural materials accumulate on roads, pavements, and cycle ways. When temperatures are negative, the ground is slippery as leaves become stuck in ice, and, when temperatures become positive again, the ground becomes slippery and muddy, covered with damp shredded leaves. In spring, roads, pavements, and cycle ways are covered with the gravel, grit, sand, and salt spread in winter to improve resistance to slipping on the ground. The service vehicles clean away and collect these residues to improve the rolling conditions and to avoid their later accumulation 
in sewers. However, the temperatures vary greatly at the beginning of spring, and cleaning operations can start only when the temperatures are stable. The conditions are therefore not optimum for the cyclists before then.

\subsection{Road service vehicles}

The objective of municipalities is to replace the fleet of polluting road service vehicles with emission-free vehicles. The municipality of Trondheim (Norway) has, for example, started to evaluate the technical performance of electric sweepers on pavements. A traditional diesel vehicle can drive up to 15 consecutive hours, whereas the Urban-Sweeper from Boschung $(3,500 \mathrm{~kg})$ tested in Norway is expected to be operational over $10 \mathrm{~h}$ (for normal use) and to be charged in $100 \mathrm{~min}$ [2]. Bad road and weather conditions may considerably reduce the operating time, which is the most critical factor for effective road maintenance in Norway.

The autonomous sweepers available on the market offer different vehicle and battery characteristics. Their weight and hopper volume varies from $150 \mathrm{~kg}$ and 601 for the small street robots (e.g. [3]) to $850 \mathrm{~kg}$ and 1501 for larger sweepers (e.g. [4]). They can cover an area from 200 to $9,000 \mathrm{~m}^{2}$ per hour, with a speed of approximately $5-8 \mathrm{~km} / \mathrm{h}$. They can sweep a width of $1,000-1,350 \mathrm{~mm}$, which in general suits the width of pavements and cycle ways well. For effective road maintenance, ideally, new solutions should be able to brush streets in autumn and spring and to remove snow in winter. Removing snow requires higher battery capacity and motor power, and very few prototypes offer this functionality. The Power Broom from Left Hand Robotics is an autonomous-removal snow vehicle with a petrol hydraulic engine [14]. The vehicle can also pick up leaves, dirt, sand and other materials with a main rotary broom, wireless GPS control, cameras and lidar and radar sensors. The autonomous streetcleaning robot from Lumebot, also equipped with cameras and sensors, is based on a carbonfree concept [15]. However, in the coldest conditions, the working time is $4 \mathrm{~h}$, and the robot must be charged for one hour, according to the manufacturer. These robots are, however, very promising for street sweeping and snow removal, and in the coming years they will quickly offer improved alternatives and capabilities.

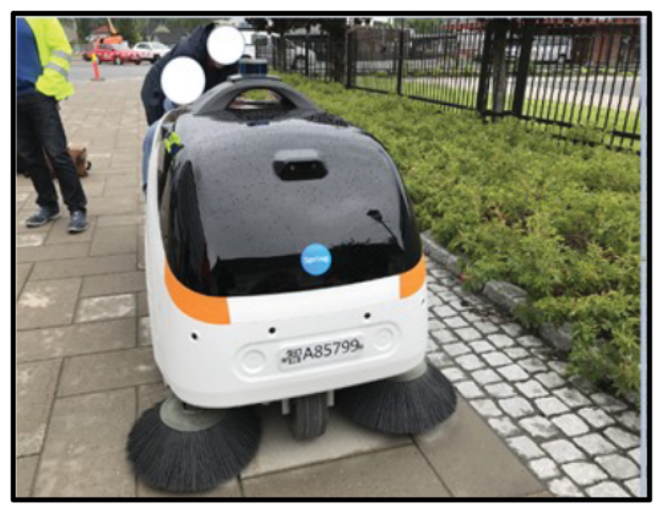

Figure 1: Autonomous sweeper S100N tested in Kongsberg in 2020. (Photography: I. Roche Cerasi). 
In this paper, we present the first evaluation in Norway of an autonomous sweeper. We tested the Spring S100N sweeper from Idriverplus Technology Co., Ltd (Fig. 1), which can perform cleaning tasks on pavements and cycle ways $[8,9,23]$.

\section{AUTONOMOUS SWEEPER}

\subsection{Spring S100N}

The Spring S100N is manufactured by Idriverplus Technology Co., Ltd, in Beijing (China) (Fig. 1) [23]. The sweeper is compact, electric, and autonomous. According to the manufacturer, more than 100 units are already in operation at universities and factories and in parks and streets in several Chinese cities. For the tests carried out in Kongsberg (Norway), a sweeper was rented from Spring Mobility GmbH, a distributor in Berlin (Germany). Applied Autonomy AS, a Norwegian company offering services for operating and implementing pilot studies and demonstrations of autonomous vehicles, was responsible for the operational tests of the sweeper.

\subsection{Limitations of the S100N sweeper}

The sweeper cannot pick up large rubbish items, ropes, ribbons, toxic and harmful substances, or hot materials [24]. If stopped because of debris on roads, it is recommended that an operator intervenes to manually lift the main brush and the side brushes to avoid damage or material deformation [24]. The sweeper cannot operate when the outdoor temperature is above $40^{\circ} \mathrm{C}$ or below $15^{\circ} \mathrm{C}$. For safety reasons, it is also forbidden to drive it in rain, snow, hail, or heavy haze. Driving with good visibility is required [24].

\subsection{Equipment and materials}

Materials: S100N has a gross weight of $395 \mathrm{~kg}$, a width of $927 \mathrm{~mm}$ and a height of 1,199 mm [24]. The sweeper has three wheels made of hard rubber tyres. For the cleaning tasks, the machine is equipped with a main brush and two side brushes made of plastic material. These brushes must be checked every 2 weeks and replaced when their diameter is under the required values [24]. The speed of rotation of the brushes cannot be changed; the main brush has a standard rotational speed of 600 revolutions per minute (rpm) and side brushes $140 \mathrm{rpm}$ [24]. The tension of the conveyor belt must be checked every $40 \mathrm{~h}$ to ensure efficient cleaning [24]. Under the machine there are four rubber skirts that protect the main brush, and these must be checked every 2 weeks. The height of the rubber skirts above the ground can be adjusted, and it is recommended that the side and back skirts are fixed 1-2 mm above the ground [24]. The dust filter and rubbish scraper must be also cleaned every 2 months, and the filter elements must be replaced regularly [24]. A vibrating motor connected to the dust filter shakes off the dust every hour. The machine stops when completing this task. The machine is supplied with a standard pipe that can be connected to a water valve under the machine to fill the water tank. This tank can be filled with maximum of 601 of water and emptied at the end of the day by opening the discharge valve.

Operating system: The Ubuntu Linux operating system must be updated regularly, and the version V16.04 is used until June 2024 [9]. The over-the-air software (V1.3.17.0) is an important component for updating the software and providing security and Wi-Fi access [9]. 


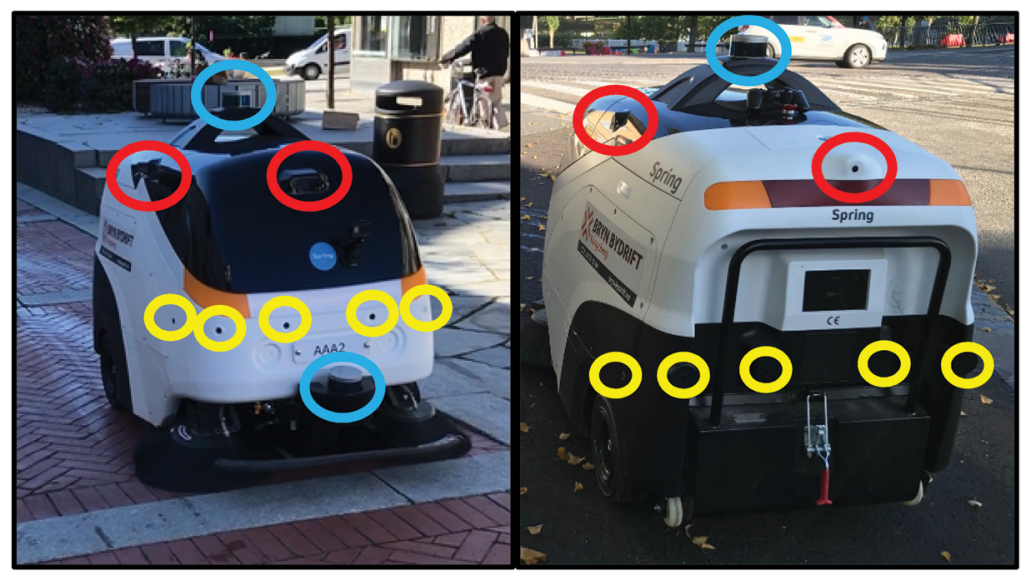

Figure 2: Detection sensor position of the Spring S100N: four cameras (red), two lidar systems (blue) and 12 ultrasonic radar sensors (yellow). (Photography: I. Roche Cerasi).

Driving and detection systems: The Spring S100N is equipped with multi-perception fusion technology [24]. This technology includes several sensors and cameras (wide angle and highdefinition camera, lidar and ultrasonic radar) combined with software algorithms optimising the perception system [24]. Figure 2 shows four cameras (red), two lidar systems (blue) and 12 ultrasonic radar sensors (yellow). The device includes a UM482 navigation module developed by Unicore Communications [24]. The functional safety level of ISO 26262-ASIL D, satisfied by the $S 100 \mathrm{~N}$, requires a system with advanced recognition of the environment and driving ability with little or no human help and includes an automatic safety braking system and other vehicular automation systems.

Charging system: The sweeper is charged on a standard $220 \mathrm{~V} \mathrm{AC}$ power socket, with a cable provided with a charger and a special charging socket to plug into the sweeper. The machine can be charged in approximately $5 \mathrm{~h}$ [24]. The ternary lithium battery, containing lithium, cobalt, nickel, and manganese, has a capacity of $24 \mathrm{~V}$ and $200 \mathrm{Ah}$ or $4.8 \mathrm{kWh}$ when fully charged [24]. The maximum driving time is therefore between 5 and $8 \mathrm{~h}$, depending on the external conditions and the tasks performed. The battery life is expected to be 3 years or $20,000 \mathrm{~km}$ [24]. The sweeper must be charged in a dry environment, without major changes in weather conditions and with minimal humidity and vibration, not in direct sunlight in summer or in rainy weather [9]. According to the manufacturer, the sweeper must be charged at least every month, otherwise long rest periods may affect the battery life or lead to charging errors [9]. When the machine is not in use, it is recommended that the battery is charged to $50-80 \%$, the power button is turned off and the sweeper is parked in a place where the temperature is between $10^{\circ} \mathrm{C}$ and $35^{\circ} \mathrm{C}$ [9].

\subsection{Cleaning tasks}

The sweeper has two speed modes: $3 \mathrm{~km} / \mathrm{h}$ (low speed) and $5 \mathrm{~km} / \mathrm{h}$ (high speed). In addition, the machine can drive on slopes of up to 15 degrees [24]. With a running time between 5 and $8 \mathrm{~h}$, the machine is expected to brush on average $3,000 \mathrm{~m}^{2} / \mathrm{h} \mathrm{[24]}$. 
Manual mode: When manually driving the sweeper, the operator must be less than $3 \mathrm{~m}$ from the sweeper, otherwise the wireless connection is lost. The remote control is similar to a game remote control, allowing the operator to choose low or high speed, lift the frontal rubber skirt, switch on/off the water spreaders, and control headlights and flashing lights. With the controller, the operator can also activate the sweeper in autonomous mode.

Autonomous mode: The sweeper software was developed by Idriverplus Technology Co., Ltd. To register the route of the cleaning operations, the operator has to follow a specific procedure, and the route planning is subsequently completed by the manufacturer in China. The sweeper is connected to the Real Time Kinematic network, a satellite positioning method that provides real-time positioning with an accuracy of up to $1 \mathrm{~cm}$ in the horizontal plane and $2 \mathrm{~cm}$ in height. A mobile phone with the Chrome browser and internet access is required [22]. The mapping task of the area must be performed under good weather conditions and when there is a limited number of humans and vehicles (cars, bicycles, etc.) [22]. Objects that could move, such as parked bikes, café tables and shop signs, must be registered in the application. The operator must also find a location with a width of $3.5 \mathrm{~m}$ where the sweeper can make a U-turn in autonomous mode [22]. In addition, a place to park the sweeper and to empty the holder, with charging and water-filling facilities, is necessary [22].

Route planning: Access to the application is allowed via a username and a password provided by Idriverplus Technology Co., Ltd, and the whole mapping procedure takes approximately two working days [22]. In the first task, the 'field adaptation task', the sweeper is operated manually in the middle of the area to be cleaned. The start and return points are defined in the application. The operator must select a threshold for the battery's state of charge (SoC) of $\leq 35 \%$; when the minimum is reached, the sweeper parks at the closest return point. Other stop points can be added, such as a charging point, a dump point, and watertank-filling points. The sensors can cover an area up of $15 \mathrm{~m}$ around the sweeper. If the area to be registered is wider than $15 \mathrm{~m}$, the machine must be driven up and down until the entire area is covered [22]. This mapping procedure must be performed continuously without stopping the recording process. If the field adaptation task is interrupted, the previous registered information is overwritten, and the task must be started again (Map Collection Training Documentation, 2020). The trajectory back to the start point must be completed before starting the second task, the 'curb adaptation task'. In the 'curb adaptation task', the sweeper should be manually driven along the edges of the area to be cleaned (pavements, parking lots, cycle ways), and each boundary must be defined in the application by selecting one of the three types of boundary: insurmountable boundary $<5 \mathrm{~cm}$ high, insurmountable boundary $>5 \mathrm{~cm}$ high (with a vertical façade, such as a wall) and surmountable boundary with a height difference of $\pm 2 \mathrm{~cm}$ with no collision risk with an obstacle within $25 \mathrm{~cm}$ of the sweeper trajectory (Map Collection Training Documentation, 2020). Obstacles along the edges, such as benches, streetlights, and city rubbish bins, must be registered, and photos should be sent to the mapping team in China [22]. The sweeper in the autonomous mode will follow exactly the trajectory manually uploaded in the application. If the operator drives the sweeper too far away from the boundaries during the curb adaptation task, the sweeper will do the same in the autonomous mode (Map Collection Training Documentation, 2020). If the area has a doughnut shape, two edge trajectories have to be registered in the application, and three trajectories with a figure-of-eight (Map Collection Training Documentation, 2020). When the curb adaptation task has been completed, the data are exported via a USB key with a capacity of at least $32 \mathrm{~GB}$, and no new mapping task can be started in the meantime. The data transfer takes several minutes, and successful data transfer is confirmed on both the sweeper screen and in the application [22]. In addition, the operator must provide a document describing the 
area to be cleaned, the position of obstacles and any other details that could be relevant for the mapping team in China. A sweeping trajectory must be proposed, taking into account that the sweeper needs to turn around and does not reverse when performing the cleaning tasks (Map Collection Training Documentation, 2020). When the mapping procedure has been completed, the operator must drive the sweeper manually to the start point and load the map into the system [22]. After few minutes, the sweeper is ready to perform the cleaning tasks.

Datasets: The operator can access the following daily dataset of cleaning tasks through the application: expected and real driving time $(\mathrm{h})$, total distance driven $(\mathrm{km})$, area cleaned $\left(\mathrm{m}^{2}\right)$, average energy usage $(\mathrm{kWh})$, number of tasks and task completion $(\%)$. The selected minimum SoC (\%) and speed mode (3 or $5 \mathrm{~km} / \mathrm{h}$ ) are also provided. Mp4 video files of the cleaning tasks performed by the sweeper are also available.

\section{METHODOLOGY}

\subsection{Objectives}

The main objective was to evaluate the Spring S100N in outdoor conditions on pavements. The field experiments were planned with the intended goal of evaluating to what extent S100N sweepers could replace manned service vehicles in urban areas. Field trials were performed under realistic conditions on two pavements currently cleaned by a diesel manned vehicle throughout the different seasons of the year. In addition to the evaluation of the technical performances, different environmental and safety challenges have been identified.

\subsection{Research questions}

The research questions of the present study were:

- To what extent can autonomous sweepers replace manned service vehicles in urban areas?

- Can autonomous sweepers perform all types of cleaning task? If not, which tasks will require the intervention of an operator?

- What external conditions affect the performance of the sweeper?

- What are the challenges related to the safety and mobility of vulnerable road users? $</ \mathrm{DL}>$

\subsection{Field experiments}

The field tests were carried out in the city of Kongsberg and in line with the manufacturer's requirements. The average outside temperatures were always between $10^{\circ} \mathrm{C}$ and $20^{\circ} \mathrm{C}$.

Two types of tests were planned: tests in a closed test area and in real conditions.

- Tests in the manual mode in a closed and designated test area at a traffic station with:

O Gravel and sand;

Leaves, cones, and twigs;

O Rubbish;

O Obstacles (safety cones).

- Tests in the autonomous mode in real conditions on a pedestrian street;

- Tests in the autonomous mode in real conditions on a pavement of a steep street. 


\subsubsection{Field experiments in manual mode}

Eight different tests were carried out with a spreading of mixed gravel and sand over asphalted surfaces from approximately 160 to $600 \mathrm{~g} / \mathrm{m}^{2}$ over a distance of $10 \mathrm{~m}$. Experiments were performed at either low $(3 \mathrm{~km} / \mathrm{h})$ or high $(5 \mathrm{~km} / \mathrm{h})$ speed, with or without water spray. The efficiency was evaluated as a function of the quantity picked up by the sweeper divided by the quantity spread on the surface. Uncertainty calculations were also performed for all tests. A spreader was used to spread mixed amounts of gravel and sand. The holder can contain 601 and, according to the manufacturer, can hold $60 \mathrm{~kg}$. However, the sweeper does not have a digital weighing system or automatically emptying holder system. The holder was therefore weighed before and after each test run.

The efficiency (EFF) was expressed as follows:

$$
\operatorname{EFF}(\%)=\left(\left[\mathrm{HO}_{\text {after }}-\mathrm{HO}\right] / \mathrm{W}_{\mathrm{s}}\right) /\left(\left[\mathrm{SP}_{\text {before }}-\mathrm{SP}_{\text {after }}\right] / \mathrm{W}\right),
$$

based on the following variables:

$\mathrm{HO}=$ weight of the empty sweeper's holder $=16.75 \mathrm{~kg}$;

$\mathrm{HO}_{\text {after }}=$ weight of the sweeper's holder after brushing task;

$\mathrm{W}_{\mathrm{s}}=$ brushing width $=1 \mathrm{~m}$;

$\mathrm{SP}_{\text {before }}=$ spreader weight before spreading $(\mathrm{kg})$;

$\mathrm{SP}_{\text {after }}=$ spreader weight after spreading $(\mathrm{kg})$;

$\mathrm{W}=$ spread width of gravel and sand $(\mathrm{m})$ (based on average values of three measurement locations along the 10 -m section).

The uncertainty of the efficiency (dEFF) was calculated as follows:

$$
d E F F=d f=\sqrt{\left[\begin{array}{l}
\left(\frac{\partial \mathrm{f}}{\partial \mathrm{HO}_{\mathrm{after}}} \Delta \mathrm{HO}_{\mathrm{after}}\right)^{2}+\left(\frac{\partial \mathrm{f}}{\partial \mathrm{SP}_{\mathrm{before}}} \Delta \mathrm{SP}_{\mathrm{before}}\right)^{2}+ \\
\left(\frac{\partial \mathrm{f}}{\partial \mathrm{SP}_{\mathrm{after}}} \Delta \mathrm{SP}_{\mathrm{after}}\right)^{2}+\left(\frac{\partial \mathrm{f}}{\partial \mathrm{W}} \Delta \mathrm{W}\right)^{2}
\end{array}\right]}
$$

where: $\Delta \mathrm{HO}_{\text {after }}=\Delta \mathrm{B} \emptyset=0.01 \mathrm{~kg} ; \Delta \mathrm{SP}_{\text {before }}=\Delta \mathrm{SP}_{\text {after }}=0.05 \mathrm{~kg} ; \Delta \mathrm{W}=5$ or $10 \mathrm{~cm}$.

The width was measured with a measuring tape, so the measurement uncertainty $(\Delta \mathrm{W})$ for a low amount of gravel and sand was $10 \mathrm{~cm}$ and for a higher amount $5 \mathrm{~cm}$.

\subsubsection{Field experiments in autonomous mode}

Two streets were selected to test the S100N sweeper under real conditions: a pedestrian street in the centre of Kongsberg (Storgata) and the pavement of a steep road (slope of approximately 6\%) outside the city centre on the other side of the river (Myntgata). The Storgata pedestrian street has a length of approximately $110 \mathrm{~m}$ and is covered with red bricks and grey stones, whereas the pavement of Myntgata is asphalted and has a width of approximately $2.65 \mathrm{~m}$. The sweeper was tested over a length of approximately $160 \mathrm{~m}$ on the Myntgata pavement. All the tests started with a fully charged battery and full water tank. In both cases, the description of the fields was prepared by Applied Autonomy AS and processed by the mapping team in China. 


\section{RESULTS}

\subsection{Fields experiments in manual mode}

Gravel and sand: Table 1 presents the eight tests performed with the sweeper. The results showed acceptable values of efficiency above $80 \%$ (depending on how much gravel and sand were spread on the asphalted test lane). The low-speed mode $(3 \mathrm{~km} / \mathrm{h})$ provided better efficiency (with the current brush rotational speeds that cannot be modified) than the high-speed mode $(5 \mathrm{~km} / \mathrm{h})$, which was too high to give the sweeper enough time to collect large amounts of gravel and sand. Without water spray, too much dust swirled in the air. The results showed small differences in efficiency between the tests, from $80.8 \%$ to $98.2 \%$. For low-spreading tests, a slight difference was found between dry and wet sweeping. Watering led to sand getting stuck in small asperities in the asphalt, whereas brushing in a dry environment made the dust and sand fly into the air. For high-spreading tests, the differences were found lower than for the low-spreading tests, possibly because the gravel and sand stuck together better and therefore become easier to brush. The results showed small differences in efficiency between the tests, from $80.8 \%$ to $98.2 \%$. For low-spreading tests, a slight difference was found between dry and wet sweeping. Watering led to sand getting stuck in small asperities in the asphalt, whereas brushing in a dry environment made the dust and sand fly into the air. For high-spreading tests, the differences were found lower than for the low-spreading tests, possibly because the gravel and sand stuck together better and therefore become easier to brush. The sweeper left two lines of gravel and sand spaced from approximately $60 \mathrm{~cm}$, which corresponds to the width of the rubber skirt in front of the main brush.

Grass, leaves, cones and twigs: The sweeper was tested with four materials using the procedure above over a distance of $8 \mathrm{~m}$ (Fig. 4).

Figure 3 shows the red lines of gravel over the track after sweeping. Small changes in the design can easily solve the problem, or the height of the rubber skirt over the ground can eventually be reduced. The results showed an efficiency of approximately 90-100\% with both low- and high-speed modes: $100 \%$ of cones and leaves and $90 \%$ of grass and small twigs ended up inside the sweeper's holder. Some grass was left on the track, and a few long twigs got stuck under and on the sides of the sweeper. These were difficult to pick up when they were lying across the brushing direction.

Table 1: Effectivity of the sweeper with and without watering in the two speed modes.

\begin{tabular}{llllll}
\hline Test & Speed $(\mathrm{km} / \mathrm{h})$ & Water & Spread Gravel $/$ sand $(\mathrm{g} / \mathrm{m} 2)$ & Effectivity $(\%)$ & Uncertainty $\%$ \\
\hline 1 & 3 & No & 444 & 91.1 & 3.5 \\
2 & 3 & No & 168 & 98.2 & 8.5 \\
3 & 5 & No & 185 & 89.2 & 7.5 \\
4 & 5 & No & 604 & 87.0 & 3.2 \\
5 & 3 & Yes & 521 & 92.1 & 3.4 \\
6 & 5 & Yes & 563 & 86.1 & 3.0 \\
7 & 3 & Yes & 176 & 82.4 & 7.1 \\
8 & 5 & Yes & 161 & 80.8 & 7.7 \\
\hline
\end{tabular}




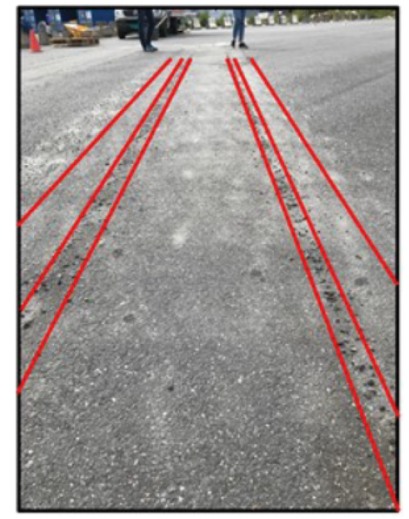

Figure 3: Gravel and sand left after brushing. (Photography: Isabelle Roche Cerasi).

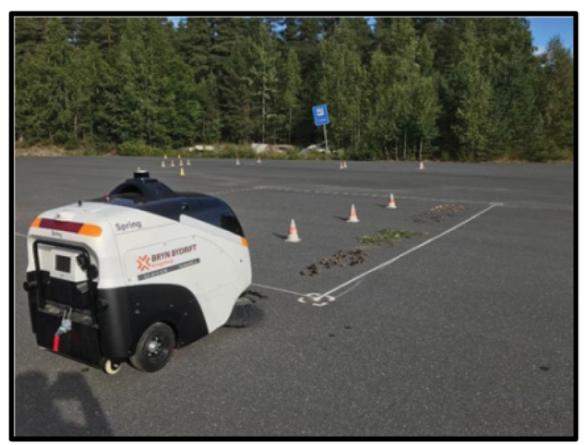

Figure 4: Tests with grass, leaves, cones and twigs. (Photography: I. Roche Cerasi).

Rubbish: The sweeper is not expected to collect large items, such as soda cans. Plastic bags or films over $20 \mathrm{~cm}$ were not tested, to prevent them from rolling around the main brush and destroying the sweeper engine. Nevertheless, four different types of rubbish were tested: broken glass, paper, plastic films, and cans, all frequently found on pavements. These types of rubbish are usually picked up by manned service vehicles without the driver having to get out of the vehicle to pick them up. After the test, the sweeper was manually moved back to check for rubbish stuck under the sweeper. Approximately $90 \%$ of broken glass and 50\% of paper and plastic films were picked up by the sweeper, but none of the cans ended up in the holder.

\subsection{Comparing tests with a manned service vehicle}

A comparison test was carried out with an Aebi Schmidt manned service vehicle operated by Bryn Bydrift, who was responsible for the cleaning operations in Kongsberg (Fig. 6). The driver swept pavements and pedestrian streets between 5 and $11 \mathrm{am}$, and he stated that he rarely has to get out of the vehicle to pick up something lying on the ground. The vehicle has a suction system and a third flexible brush on one arm. The maximum speed of the vehicle is 

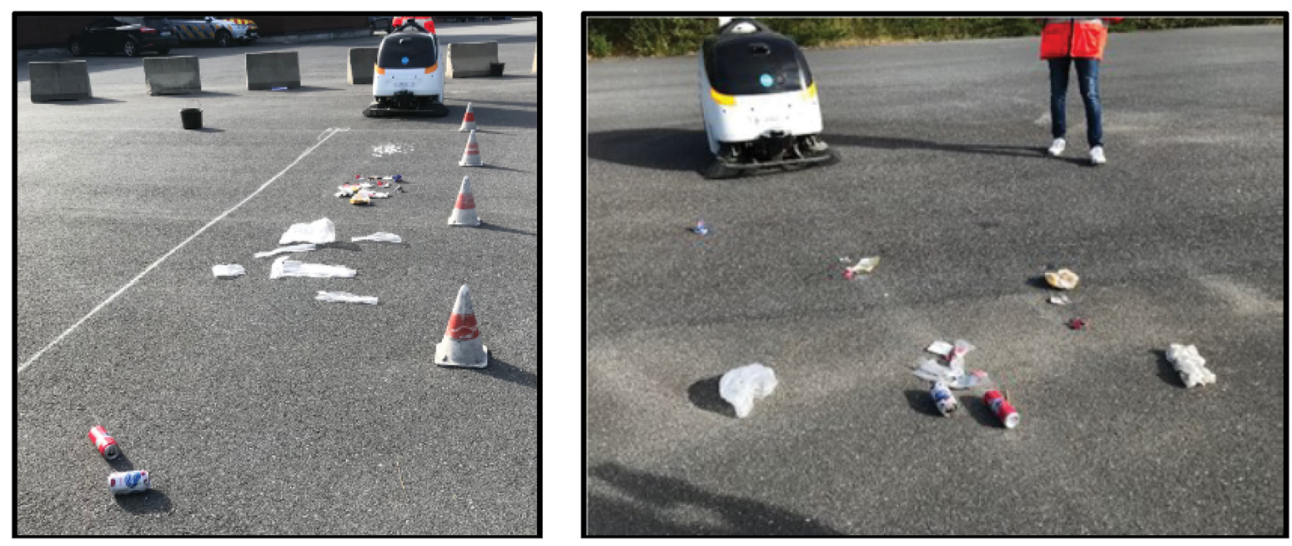

Figure 5: Tests with rubbish (broken glass, paper, plastic, and soda cans) (left). Rubbish not picked by the sweeper (right). (Photography: I. Roche Cerasi).
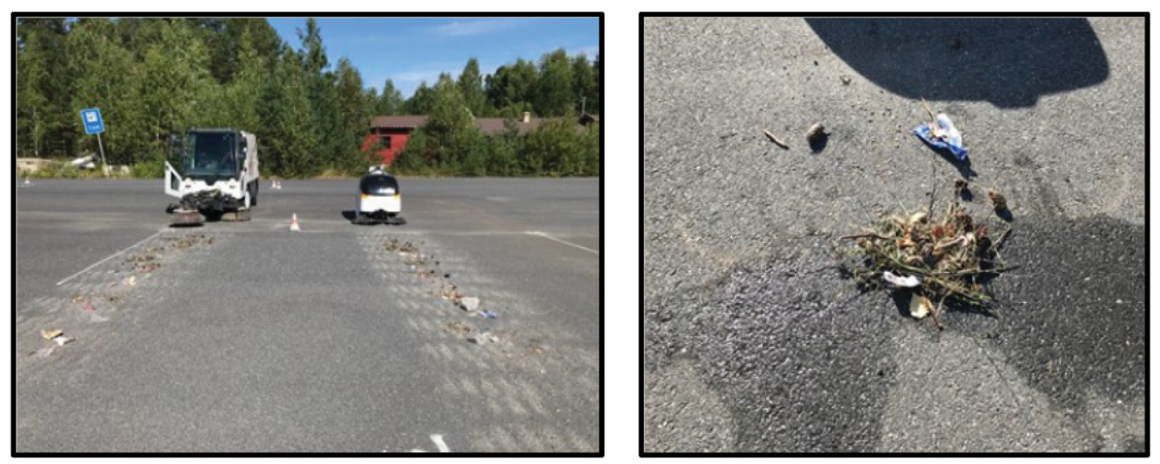

Figure 6: Comparison test with a manned service vehicle (left). Rubbish not caught up by the S100N sweeper (right). (Photography: I. Roche Cerasi).

$40 \mathrm{~km} / \mathrm{h}$, the vehicle has a gross weight of 5,500 kg. and the sweeping width is approximately $2 \mathrm{~m}$. Two similar lines of $8 \mathrm{~m}$ with gravel, sand and rubbish were prepared. Both vehicles used watering and drove at a low speed of $3 \mathrm{~km} / \mathrm{h}$. The Schmidt sweeper had $100 \%$ efficiency and picked up all the items, whereas a small amount of rubbish was left lying in front of the rubber skirt under the $\mathrm{S} 100 \mathrm{~N}$ sweeper.

\subsection{Safety function in manual mode}

The safety function of the $\mathrm{S} 100 \mathrm{~N}$ is reduced in the manual mode; the sensors located on each side of the sweeper are disabled. Figure 7 shows in yellow the two active ultrasonic sensors in manual mode. The lidar sensors, cameras or other ultrasonic sensors are not in use.

The operator must be aware of limited function when moving the sweeper around, especially in streets where there are many obstacles, such as plant pots, benches, bins, and shop signs. Figure 7 shows the tests performed with two types of cones. The machine detected only 


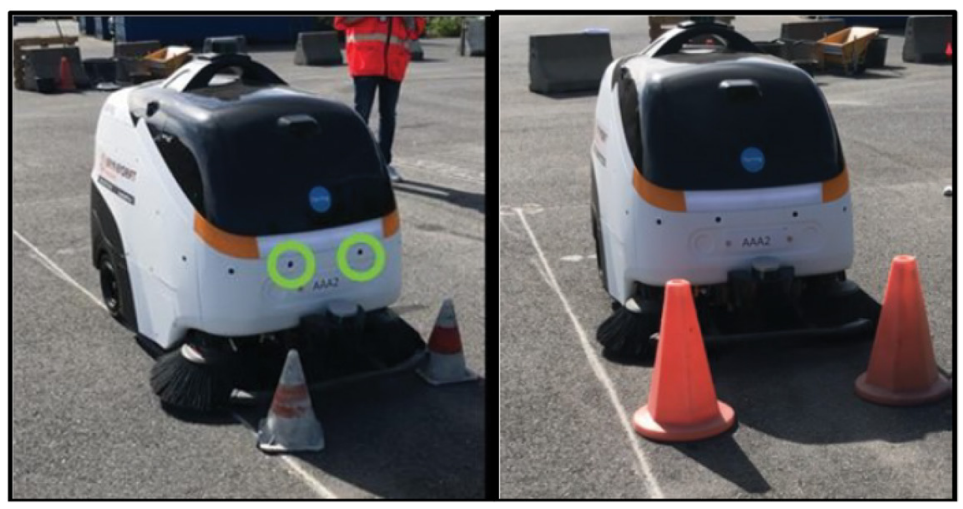

Figure 7: Tests with safety cones; $28 \mathrm{~cm}$ high cones (left) and $60 \mathrm{~cm}$ high cones (right). The detection sensors (yellow) in use in manual mode. (Photography: I. Roche Cerasi).

the $40 \mathrm{~cm}$ high cones and stopped at a distance of approximately $60 \mathrm{~cm}$. The sweeper did not detect the $28 \mathrm{~cm}$ high cones. This system might create risky situations with pedestrians and confusion if the operator expects the sweeper to stop automatically (Fig. 7).

\subsection{Field experiments in autonomous mode}

\subsubsection{Pedestrian street}

The tests on the Storgata pedestrian street were conducted over 4 days in September 2020. Figure 8 shows the task performed by the sweeper; each task includes four rounds and a return to the starting point. The sweeper started to brush the edges of the field to be cleaned (Round 1, blue line on Fig. 8) and then the centre of the field (Round 2, orange line on Fig. 8). The third round was inside the field (Round 3, green line on Fig. 8) and the last was the shortest round, with the aim of cleaning an area in the middle of the pedestrian street (Round 4, black line on Fig. 8).

The sweeper completed approximately 12 tasks per day and stopped when the battery threshold SoC of $20 \%$ was reached. Observations showed that the red bricks, grey stones, and metal manhole covers did not pose any major challenges for the sweeper. The sweeper avoided locations of obstacles (mostly bicycles) present during the field registration even if they were no longer there.

Battery state of charge and tank water level: The average values of the tasks performed showed that the sweeper brushed on average $98.5 \%$ of the field registered in the application and approximately $892 \mathrm{~m}^{2}$. The sweeping time per task was approximately $26.5 \mathrm{~min}$. The sweeper consumed per task approximately $7.0 \%$ of the battery power and $10 \%$ of the water in the tank. To clean the pedestrian street, approximately $8.6 \%$ of the battery SoC per $1,000 \mathrm{~m}^{2}$ was required. Figure 9 shows how the sweeping tasks affected the battery SoC and tank water level. The water tank was empty after a driven distance of $7.9 \mathrm{~km}$. The sweeper collected a total of $2 \mathrm{~kg}$ of leaves, dust, and gravel, and 12 tasks were necessary to reach the battery threshold SoC of $20 \%$. The sweeper stopped and returned to the start point after the first round of the 12th task. 

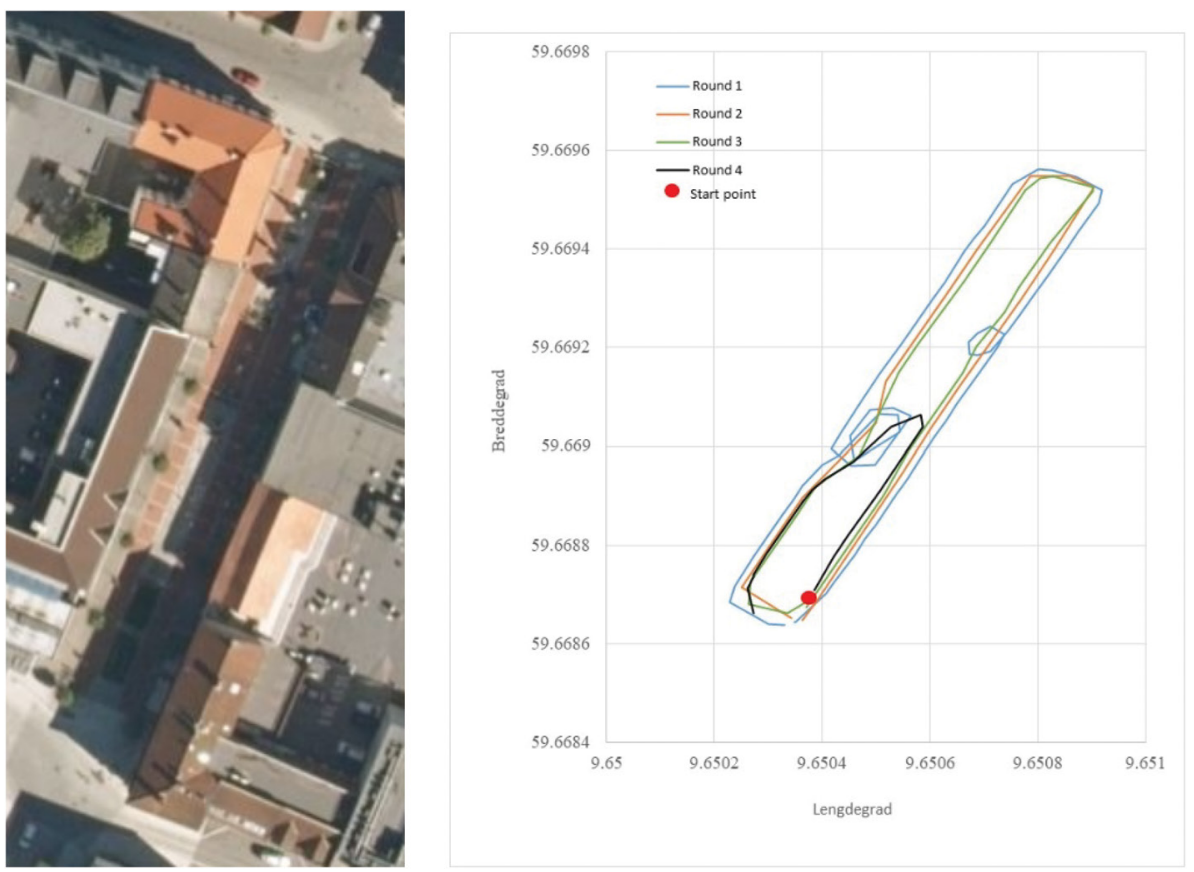

Figure 8: Four cleaning rounds on the Storgata pedestrian street.

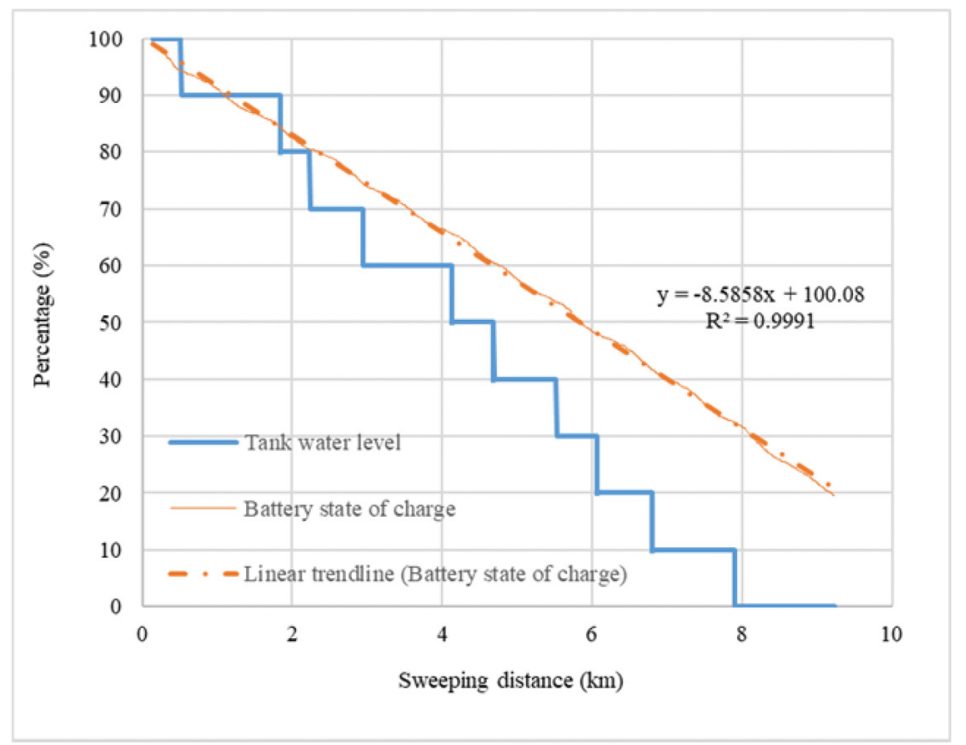

Figure 9: Battery state of charge and tank water level as functions of sweeping distance over 12 tasks. 
Speed: Figure 10 shows the speed profiles of the fourth of the 12 tasks. This task was fully completed (99\%) and took $21.6 \mathrm{~min}$ for the sweeper to complete. Table 2 shows the average and maximum speeds of the sweeper during the four rounds in high-speed mode. The highest speeds were reached in Rounds 2 and 3 (1.52 and $1.54 \mathrm{~m} / \mathrm{s}$, respectively), when the sweeper accelerated on the straight lines of the pedestrian street (Figure 10).

In Round 1, the sweeper had large accelerations $(1.38 \mathrm{~m} / \mathrm{s})$ when cleaning twice one of the two small areas in the middle of the street (Fig. 10).

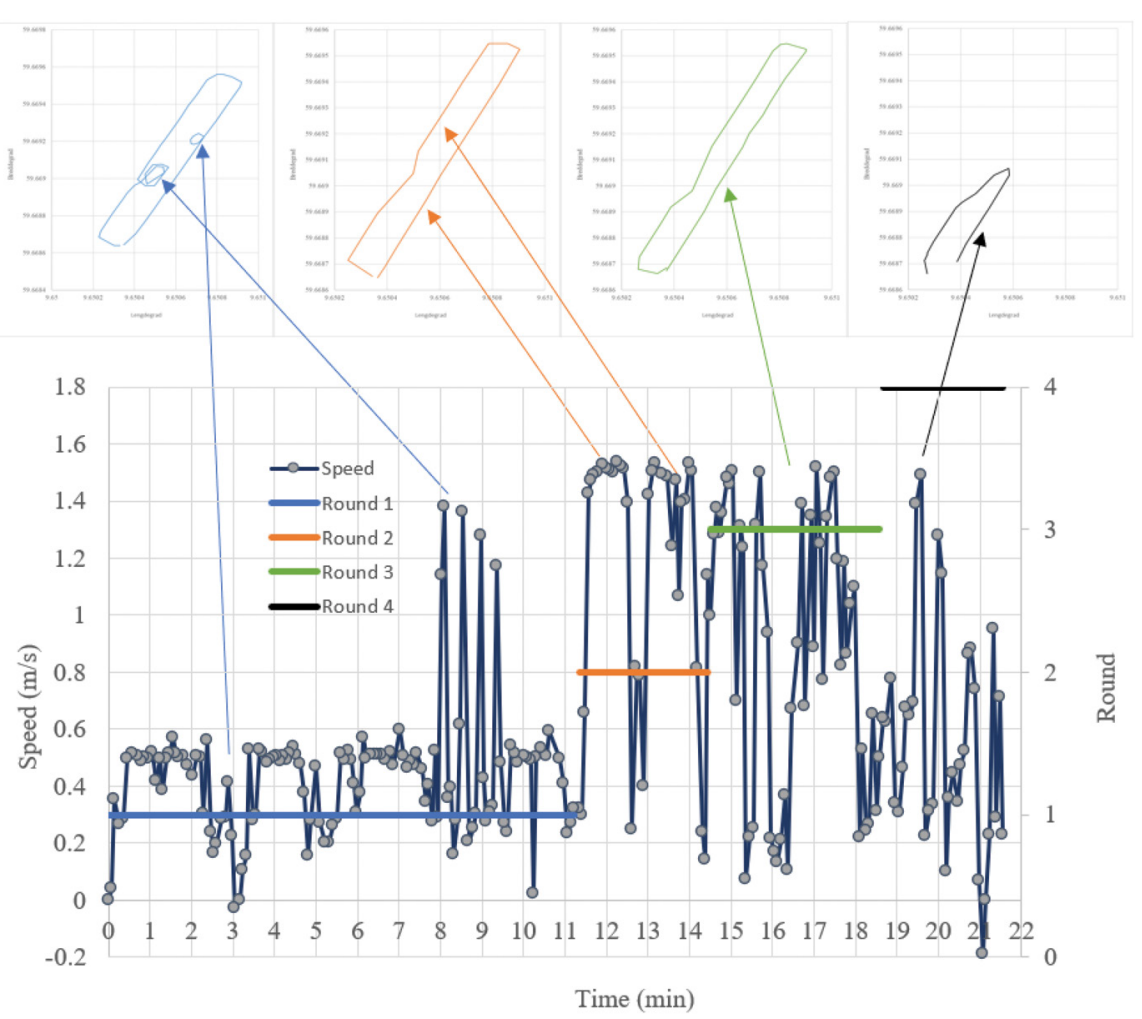

Figure 10: Speed profiles in high-speed mode for the four rounds of the sweeping task on the Storgata pedestrian street.

Table 2: Average speed $(\mathrm{m} / \mathrm{s})$ of the sweeper (high-speed mode) during four rounds on the Storgata pedestrian street.

\begin{tabular}{lll}
\hline Round & Average speed $(\mathrm{m} / \mathrm{s})$ & Maximum speed $(\mathrm{m} / \mathrm{s})$ \\
\hline 1 & 0.43 & 1.38 \\
2 & 1.17 & 1.54 \\
3 & 0.88 & 1.52 \\
4 & 0.56 & 1.49 \\
\hline
\end{tabular}




\subsubsection{Pavement on a steep road}

The sweeper was tested in low-speed mode on one of pavements of the steep Myntgata road. The pavement is bordered by walls, stairs and private property entrances, and there are lamp posts, bins, and benches along it. Little rubbish is usually found on this street, and most of it is comprised of leaves and pine needles. Fig. 11 shows that each task includes two rounds with a return to the starting point. The sweeper first brushed the edges of the planned area (Round 1, blue line) and then the centre of the area (Round 2, orange line). The sweeper drove a total length of $160 \mathrm{~m}$ between the start point and the top of the street.

The sweeper cleaned the street for 2 days and returned to the start point when the battery threshold SoC of $20 \%$ was reached. The sweeper completed 14 tasks per day and stopped during the 15th task, when the threshold was reached. The water tank was empty during the 12th task.

Battery state of charge and tank water level: The average values for the tasks performed showed that the sweeper brushed on average $96 \%$ of the field registered in the application and approximately $653 \mathrm{~m}^{2}$. The sweeping time per task was approximately $20.3 \mathrm{~min}$. The sweeper consumed per task approximately $5.5 \%$ of the battery power and $6.4 \%$ of the water in the tank. To clean the pedestrian street, approximately $8.5 \%$ of the battery per $1,000 \mathrm{~m}^{2}$ was therefore required.

Figure 12 shows that the sweeper stopped sweeping after driving a distance of $8.8 \mathrm{~km}$. The sweeper picked up $2.7 \mathrm{~kg}$ of leaves, gravel, and dust. The water tank was empty after $6.8 \mathrm{~km}$,
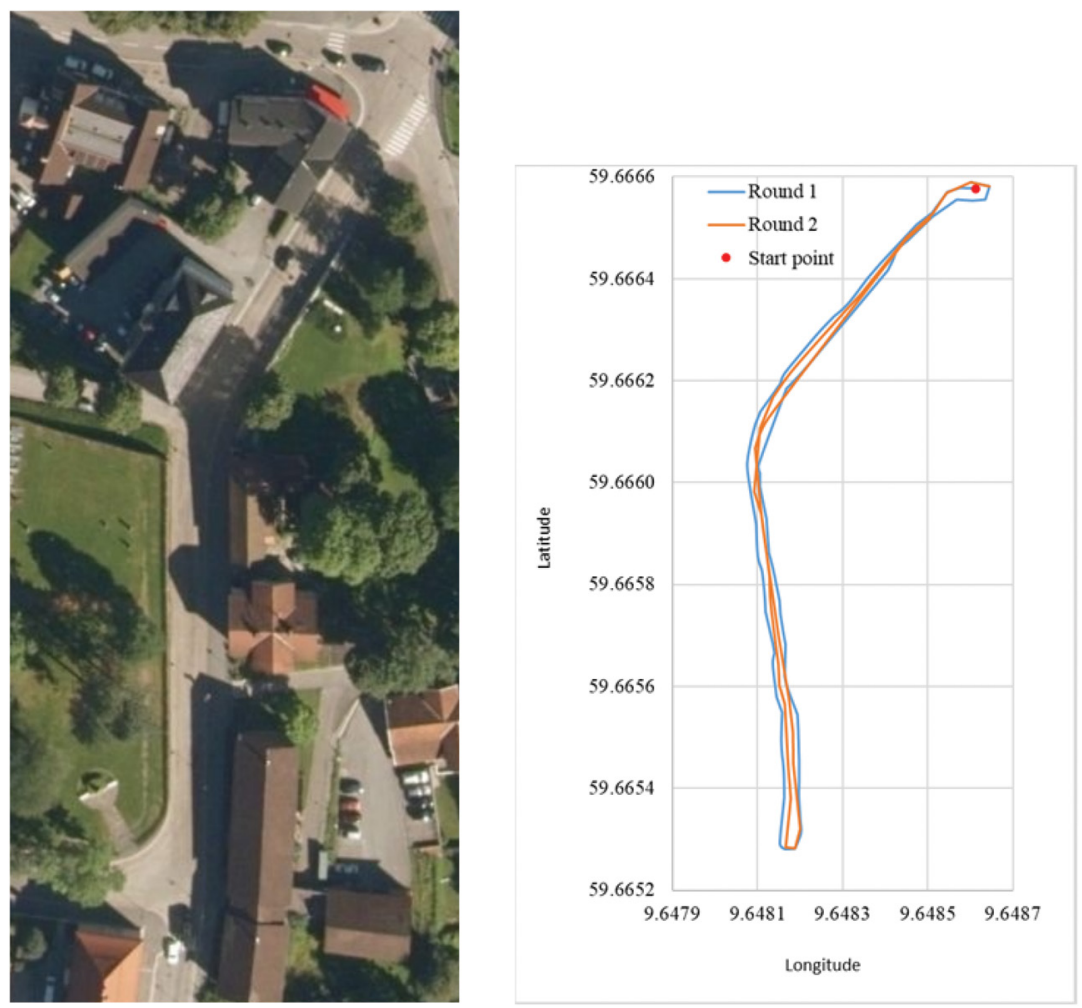

Figure 11: Task with two rounds performed in the Myntgata street. 


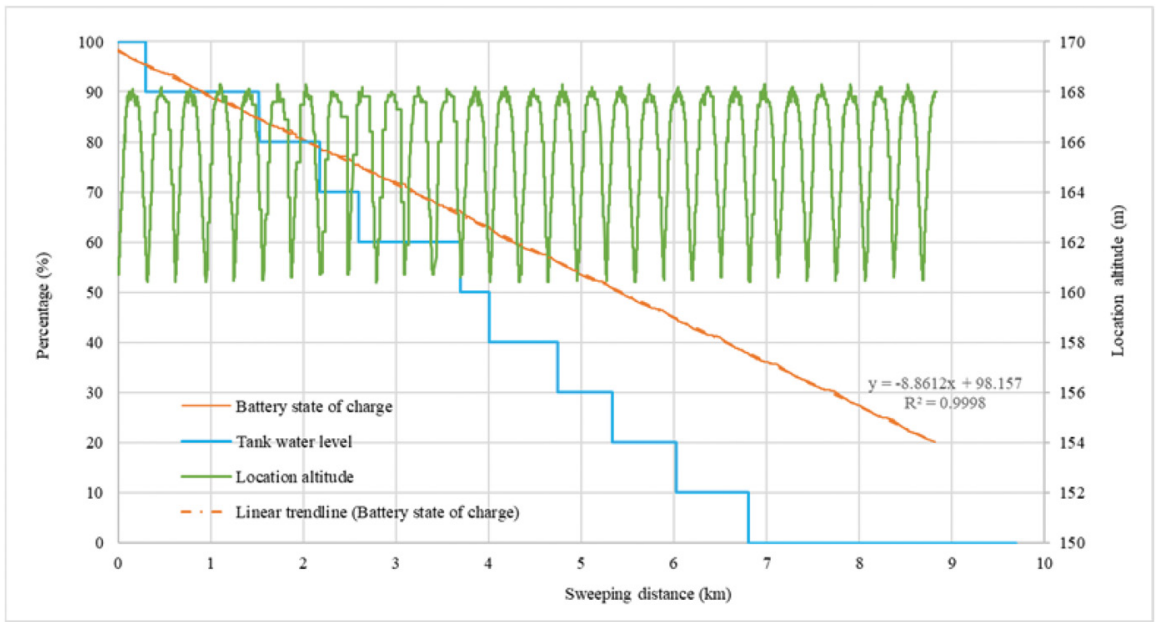

Figure 12: Battery state of charge and tank water level as a function of sweeping distance over 15 tasks in the Myntgata street.

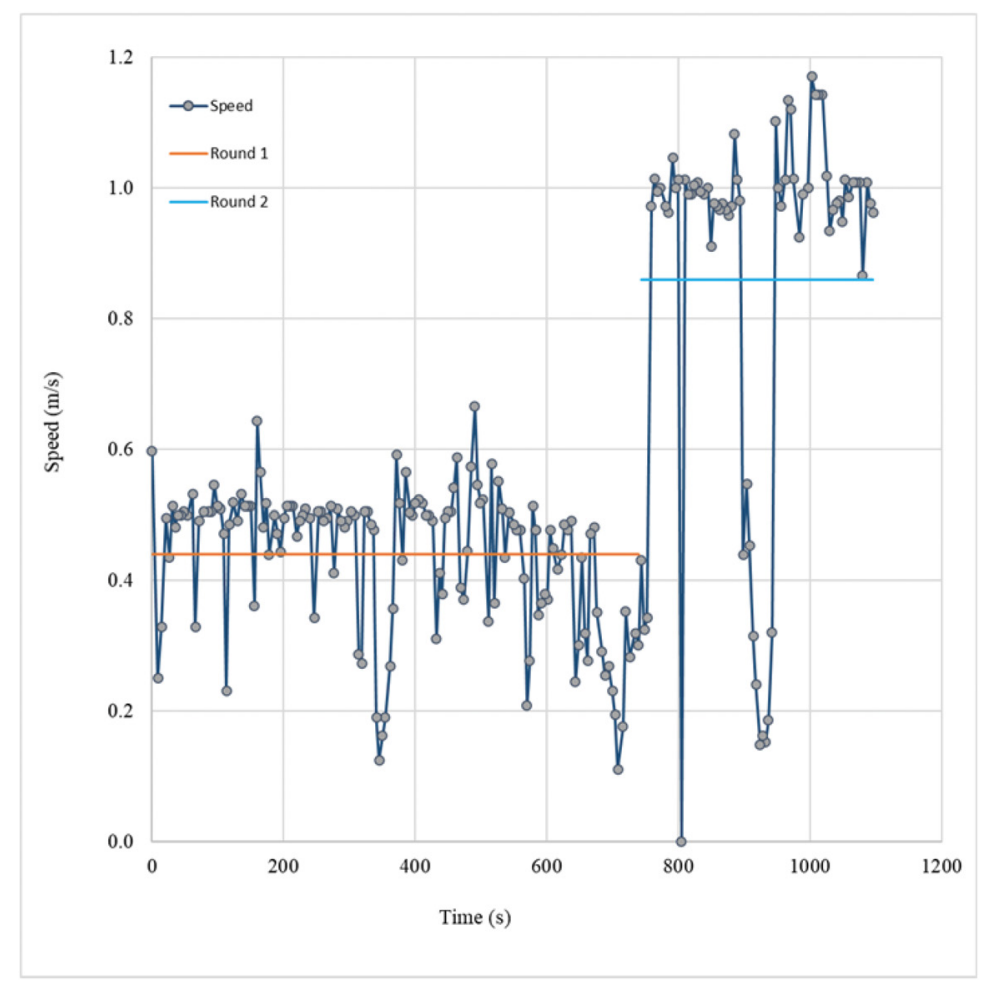

Figure 13: Speed profiles of the sweeper during two rounds of a task in the Myntgata street. 
during the 12th task (blue line, Fig. 12). The green line indicates the altitude of the sweeper when performing the tasks, and the orange line the linear decrease of the battery SoC when driving up and down the pavement.

Speed: Fig. 13 shows an example of the speed profile of the sweeper during two rounds. The sweeper has an average speed of $0.44 \mathrm{~m} / \mathrm{s}$ in Round 1 and $0.89 \mathrm{~m} / \mathrm{s}$ in Round 2. During Round 2, it stopped once (time $=804.5 \mathrm{~s})$ and accelerated from 0 to $1.01 \mathrm{~m} / \mathrm{s}(3.65 \mathrm{~km} / \mathrm{h})$ in $5.3 \mathrm{~s}$. On the descent to the starting point, it reached a maximum speed of $1.26 \mathrm{~m} / \mathrm{s}$. On average, the sweeper exceeded the speed of $4 \mathrm{~km} / \mathrm{h} 1.8$ times per task.

\subsubsection{Conflicts with motorised vehicles and vulnerable road users}

Material damage: Although the sweeper warns road users about its movements with predefined voice messages, different conflict situations still occurred. The sweeper was damaged when tested in the autonomous mode on the pedestrian street, when no operator was present. Our hypothesis is that the sweeper did not detect a truck ramp and was damaged by it when a truck was parked on the pedestrian street to deliver goods (Fig. 14). A truck ramp is a thin and reflective horizontal surface and is therefore difficult for the sensors to detect.

Error messages: The sweeper sent several error messages and stopped frequently during the tests. Most of the messages had unknown causes. One of the error messages was related to the shaking of the main brush and the filter ('Sweeper is shaking off the dust. Please wait patiently'). In addition, the dust on the sensors was frequently removed by the operator, without knowing if this was an issue.

Driving off the curb: The sweeper drove off the curb when turning at the start point and could not drive back on its own to the pavement. The boundaries were not properly defined by the operator when performing the curb adaptation task in the application. The operator defined the curb with 'soft' boundaries instead of 'strict' ones. The sweeper can drive up to $20 \mathrm{~cm}$ outside soft boundaries, while strict ones allow only up to $5 \mathrm{~cm}$.

Speed: The tests showed that the sweeper often drove and accelerated too fast. Observations showed that it was easier for people to walk by when the sweeper drove slowly. Moreover, pedestrians dared to pass it when they had enough space to do so. They were clearly more careful when the sweeper was driving in the middle of the pavement. They often stopped without knowing where to go.

Conflicts with vulnerable road users: A visually impaired person walking on the pavement crossed the sweeper. The sweeper detected and warned him to be careful, but he could not understand where the unknown voice came from and was confused. One of the observers had to intervene to help him, as he almost fell off the curb when moving backwards away from the
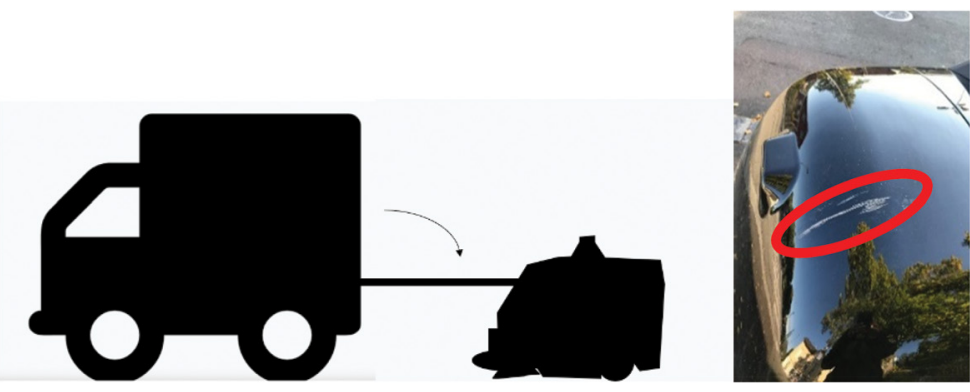

Figure 14: Hypothetical scenario of the collision on the pedestrian street. 
voice. Several individuals with four-wheeled walkers or electric wheelchairs encountered the sweeper and were not disturbed when there was enough space for them to pass by it (Fig. 15A). A man with reduced mobility had difficulty standing on the uneven stones at the paved entrance of a house while waiting for the sweeper to drive by. Cyclists or people with skateboards or electric scooters who went down the pavement, passed by the sweeper at high speed (Fig. 15B and C). When there was plenty of room for both parties, no conflict was noted (Fig. 15A). However, the sweeper detected them passing by but stopped too late and delivered the message 'be careful' even if they were already far away. When the sweeper drove between a lamp post and a bench, there was not enough space for cyclists and pedestrians to pass by; they slowed down or stopped, waiting to continue on their way (Fig. 15D). In some cases, the sweeper blocked the pavement, and people did not understand what to do; they did not know that they had to move away from the sweeper to allow it to continue on its way. Some of them (including children) chose to use the cycle lanes on the street.

When the sweeper was passing by a bench, it made no difference whether someone was sitting on it (Fig. 15E). The sweeper could not distinguish between the bench and a person sitting on it. Consequently, the sweeper kept a very short distance, approximately $10 \mathrm{~cm}$, from the knees of the person sitting on the bench and brushed their shoes. The same issue was noted when the sweeper drove along a wall (Fig. 15F). and a person was standing against it: if the sweeper detected the person, it warned with the 'be careful' message and continued on its way, but, when it did not detect the person, it drove very close to them and brushed their shoes with the side brush.
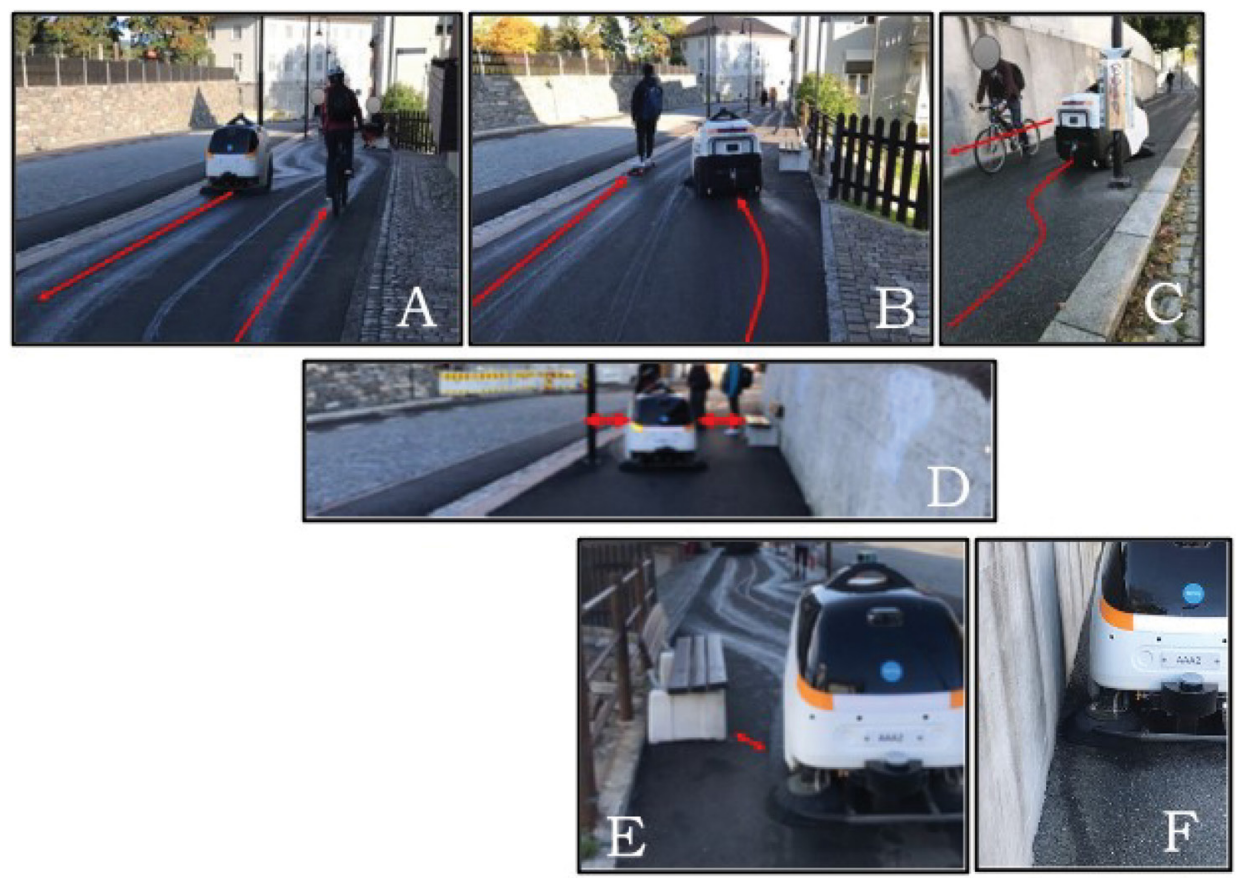

Figure 15: Conflicts between vulnerable road users and the sweeper on the pavement of a steep road. (Photography: I. Roche Cerasi). 


\section{DISCUSSION}

The results presented in this research paper show that autonomous sweepers could replace manned service vehicles in urban areas in the near future. They could sweep the street pavements more frequently and replace manned service vehicles for boring and repetitive cleaning tasks that do not require the presence of a human being. Even if the sweepers on the market today can still be considered as prototypes, they are promising for achieving sustainable development. Cities and municipalities need to find cost-effective and environmentally friendly solutions and controlling fleets of non-pollutant vehicles from a control room could help in achieving this goal.

Concerning large rubbish items, the sweeper could eventually leave the accumulated rubbish at a specific location on pavements, or alternatively the sweeper could identify and avoid them on pavements. However, large amounts of rubbish greatly reduce the efficiency of the sweeper and could even stop it. A combination of watering and presence of sand might have the effect of gluing the rubbish together under the sweeper. Shards of glass were collected by the sweeper. However, when the hard rubber wheels run over them, they broke into smaller pieces and spread around the sweeper, and, if this happened near pedestrians, it would jeopardise safety. New wheel materials or designs must be considered in the future to reduce the risk of such accidents; for example, moving the wheel behind the rubber skirt. Another solution might be that the sweeper recognises and avoids shards of glass or adapts its behaviour.

The size of robot sweepers is adapted to pavements and cycle ways, although our study showed that several issues need further investigation. For example, for safety reasons and for preventing the restriction of pedestrians' and cyclists' movement, it would be better if the sweeper could detect vulnerable road users before meeting them and evaluate their speed in order to adapt its behaviour. The sweeper could then park at the side and wait for them to pass by it when there is not enough room on the pavement. This would require the sweeper to demonstrate human-like behaviour, and this will be feasible with artificial intelligence technology and machine learning in the coming years. Another solution may be that the sweeper cleans the pavements early in the morning; however, the repetitive tasks would require an improvement in noise levels through better design and technologies, and the time of operation does not prevent safety issues.

The same issue detection issue occurs when the sweeper cannot identify a person sitting on a bench or standing against a wall, which shows that, without advanced object recognition, it would be critical to ensure safe operations when the sweeper drives close to urban furniture or makes backward manoeuvres. Another safety issue to be considered is cleaning in front of stairs, house entrances or small alleyways between buildings, where there is no good visibility for either the road users or the sweeper. The sweeper cannot detect that someone is approaching from hidden places and so stops only when the person is close to it; this leads to dangerous conflict situations, which require road users to be attentive and to adapt their behaviour to the sweeper. The main concern is the reactions of road users who could be surprised by the sweeper. The ideal situation would be that the sweeper stops before passing these locations, detects eventual approaching pedestrians and cyclists, gives them room to cross and then drives when the passage is clear.

\section{CONCLUSION}

In the present study, we tested an autonomous sweeper, the Spring S100N developed by Idriverplus Technology Co., Ltd. The main objective of the study was to evaluate the Spring S100N in outdoor conditions on pavements. The field experiments were planned with the 
intended goal of evaluating to what extent S100N sweepers could replace manned service vehicles in urban areas.

The field experiments showed a real potential for replacing manned service vehicles in urban areas. In the manual mode, they provided satisfactory results: the sweeper collected gravel and sand with an efficiency from $80.8 \%$ to $98.2 \%$. We recommend using the lowspeed mode with wet sweeping to avoid the dust flying into the air and being deposited on sensors and cameras. Some design changes are required to avoid leaving too much gravel on the ground. The sweeper could sweep the same area several times, but this could create unnecessary noise levels for the population. Concerning the collection of natural materials and rubbish, the tests confirmed that large items are difficult for the sweeper to pick up. However, it collected leaves, cones and twigs with no major difficulty. We recommend avoiding the sweeper sweeping areas with large numbers of pine cones or long twigs. In addition, the safety function in manual mode may confuse the operator, who may expect the sweeper to stop in particular situations. A better user-friendly interface should be also developed on the sweeper, and clear messages should be sent to the operator.

The field experiments in the autonomous mode provided insights into the limitations of the sweeper for performing equivalent cleaning tasks of a manned service vehicle. The sweeper cleaned the pedestrian street and the pavements with great satisfaction. However, we recommend investigating further challenges related to the interactions with the vulnerable road users. A better solution must be found for ensuring safety and for avoiding disturbing the pedestrians' and cyclists' movement on pavements. For example, better warning systems, headlights and voice messages may contribute to ensuring that vulnerable road users anticipate where the sweeper is going to move and what it is waiting for.

Prototypes of autonomous sweepers must be developed in close collaboration with the different stakeholders involved in road operations and maintenance. The tests performed in this study clearly indicate the requirements to be satisfied in order to ensure their safe operation and the maintenance of pavements.

\section{ACKNOWLEDGEMENTS}

This research study was funded by the Norwegian Public Roads Administration (NPRA). First, the author would like to thank Katja-Pauliina Skille, Stein Brembu, Bård Nonstad, Million Kiros Weldu and Liv Øvstedal (NPRA) for extending support in this research study. Second, the author would like to thank the steering committee of Test-arena Kongsberg City\&Lab, Elisabeth Stuggevik (NPRA), Ingar Vaskinn (Kongsberg Municipality) and Olav Madland (Applied Autonomy AS) for their large support in providing test facilities. Third, special thanks to Rebecca Ronke (Applied Autonomy AS) for preparing the field mapping in the application, sharing her experience with the sweeper, and being always available for discussions and support. We would like to thank Damien Declercq from Spring Mobility $\mathrm{GmbH}$ (Germany) who provided us information and data via emails and meetings. Special thanks to Bryn Bydrift, that shared with us their experience about their road operations and maintenance in Kongsberg (Norway).

\section{REFERENCES}

[1] BEVEGELSE programme. NPRA https://www.vegvesen.no/fag/fokusomrader/forskninginnovasjon-og-utvikling/pagaende-programmer-og-prosjekter/bevegelse.

[2] Boschung. Urban-Sweeper. https://www.boschung.com/product/urban-sweeper-s2-0/.

[3] DustClean Robotech srl. https://www.robotechsrl.com/dustclean-en-robot-sweeper/.

[4] ENWAY. Blitz One. https://enway.ai/en/. 
[5] Fenre, M.D., Klein-Paste, K., Bicycle rolling resistance under winter conditions. Cold Regions Science and Technology 187 (2021) 103282, 2021. https://doi.org/10.1016/j. coldregions.2021.103282.

[6] Nordin, L., Arvidsson A.K., Are winter road maintenance practices energy efficient? A geographical analysis in terms of traffic energy use. Journal of Transport Geography, Vol. 41, pp. 163-174, 2014.

[7] Government, Cycling and Walking. https://www.regjeringen.no/no/sub/stedsutvikling/ ny-emner-og-eksempler/sykkeltrafikk/id612408/, 2016.

[8] Idriverplus Technology Co, Ltd. http://www.idriverplus.com/.

[9] Idriverplus Technology Co, Ltd. Map collection training documentation with H5. 2020.

[10] Karlsson, Roche Cerasi, I., Rise, T., Kartlegging av nye kjøretøy-eller maskinteknologier for vinterdrift av gang-og sykkelveger. SINTEF Report 2020:00525, 2020. ISBN 97882-14-06506-0.

[11] Kramberger, T., Žerovnik, J., A contribution to environmentally friendly winter road maintenance: optimizing road de-icing. Transportation Research Part D: Transport and Environment, Vol. 13, Issue 5, pp. 340-346, 2008. doi.org/10.1016/j.trd.2008.03.007.

[12] Kummeneje, A.-M., Ryeng, E. O., Rundmo, T., Seasonal variation in risk perception and travel behaviour among cyclists in a Norwegian urban area. Accident Analysis \& Prevention, 124, pp. 40-49, 2019. Doi: 10.1016/j.aap.2018.12.021.

[13] Kummeneje, A.M., Risk Perception, Worry, Attitudes Towards Safety, and Behaviour among Norwegian Cyclists and Pedestrians. Doctoral theses, NTNU. 2020:390, 2020.

[14] Left Hand Robotics. https://lefthandrobotics.com/.

[15] Lumebot. https://www.linkedin.com/company/lumebot/about/.

[16] Min, J., Fu, L., Usman, T., Tan, Z., Does winter road maintenance help reduce air emissions and fuel consumption?. Transportation Research Part D: Transport and Environment Vol. 48, pp 85-95, 2016. https://doi.org/10.1016/j.trd.2016.08.010.

[17] Mitra, R., Khachatrian, A., Hess, P. M., Do new urban and suburban cycling facilities encourage more bicycling?. Transportation Research Part D: Transport and Environment, Vol. 97, 2021. https://doi.org/10.1016/j.trd.2021.102915.

[18] Perrier, N., Langevin, A., Campbell, J.F., A survey of models and algorithms for winter road maintenance. Part I: system design for spreading and plowing. Computers \& Operations Research, Vol. 33, Issue 1, pp. 209-238, 2006. https://doi.org/10.1016/j. cor.2004.07.006.

[19] National transport plan 2022-2033, https://www.regjeringen.no/no/tema/transport-ogkommunikasjon/nasjonal-transportplan/id2475111/, 2021.

[20] Norwegian Public Roads Administration,. Winter Road Maintenance. https://www. vegvesen.no/fag/veg+og+gate/drift+og+vedlikehold/Vinterdrift, 2020.

[21] Road directorate Standard manual R610. Published by NPRA. ISBN: 978-82-7207655-8 https://www.vegvesen.no/_attachment/61430/binary/964067?fast_title=H\%C3 \%A5ndbok+R610+Standard+for+drift+og+vedlikehold+av+riksveger.pdf, 2014.

[22] Ronke, R., Procedure for mapping an area for autonomous operations of the Spring S100N sweeper. Applied Autonomy AS 2020.

[23] Spring Mobility GmbH. https://getspring.co/.

[24] Spring - S100N User Manual, (Spring Mobility GmbH). 2020.

[25] Test-arena Kongsberg - City\&Lab. https://www.cityandlab.no/.

[26] Zítková, J., Hegrová, J., Anděl, P., Bioindication of road salting impact on Norway spruce (Picea abies). Transportation Research Part D: Transport and Environment, Vol. 59, pp. 58-67, 2018. DOI: 10.1016/j.trd.2017.12.010. 